\title{
ANALISIS DAN DESAIN SISTEM INFORMASI PENGOLAHAN DATA BANTUAN PANGAN NON TUNAI PADA KECAMATAN CURUG
}

\author{
Rohmat Taufiq $^{1}$, Nadia Resti Kusniati ${ }^{2}$, Supriyono ${ }^{3}$ \\ ${ }^{1,2}$ Teknik Informatika, Fakultas Teknik, Universitas Muhammadiyah Tangerang \\ ${ }^{3}$ Sistem Informasi, Fakultas Teknik, Universitas Muria Kudus
}

\section{Article Info:}

Dikirim: 04 Oktober 2019

Direvisi: 31 Desember 2019

Diterima: 31 Desember 2019

Tersedia Online: 31 Desember 2019

Penulis Korespondensi:

Rohmat Taufiq

Universitas Muhammadiyah

Tangerang, Banten, Indonesia

Email: Rohmat.taufiq@umt.ac.id

\begin{abstract}
Abstrak: Kecamatan Curug merupakan instansi pemerintah yang menyalurkan Bantuan Pangan Non Tunai kepada warga miskin, dengan jumlah data warga yang terbilang banyak data tersebut disimpan menggunakan program Microsoft Excel. Laporan yang dihasilkan saat ini masih terdapat banyak kesalahan pada data peserta, banyak terjadi redudancy data dikarenakan kesalahan saat menginput. Hasil laporan tidak terkelompok membuat petugas mengalami kesulitan saat ingin mencari dan memperbaiki kesalahan data. Selain itu sering terjadi kehilangan data serta sulitnya Staff Kecamatan untuk mengetahui informasi laporan data karena keterlambatan dalam pembuatan laporan dari Pendamping BPNT. Hal tersebut membuat kinerja petugas menjadi terhambat. Untuk mengatasi permasalahan tersebut, penulis mengusulkan aplikasi Sistem Informasi Pengolahan Data BPNT menggunakan metode analisa berorientasi objek dan alat bantu Unified Modelling Language (UML). Sistem ini dibuat untuk membantu mempercepat proses penyelesaian pekerjaan Pendamping dan Staff Kecamatan, serta mengurangi resiko kesalahan yang mungkin terjadi.
\end{abstract}

Kata kunci: pengolahan data; bantuan pangan non tunai; UML.

\begin{abstract}
Curug Subdistrict is a government agency that distributes Non-Cash Food Assistance to poor citizens, with a large amount of citizen data stored using the Microsoft Excel program. Reports generated at this time there are still many errors in the participant data, many data redundancy occurs due to errors when inputting. Unclassified report results make it difficult for officers to want to find and correct data errors. In addition, data loss often occurs as well as the difficulty of District Staff to find out information on data reports due to delays in preparing reports from BPNT Companions. This makes the performance of officers hampered. To overcome these problems, the authors propose the application of BPNT Data Processing Information Systems using object-oriented analysis methods and Unified Modeling Language (UML) tools. This system was created to help speed up the process of completing the work of Companion and District Staff, and reduce the risk of errors that might occur.
\end{abstract}

Keywords: data processing; non-cash food aid; UML. 


\section{PENDAHULUAN}

Di era serba-teknologi kini, banyak manfaat yang didapatkan dari teknologi yang terus berkembang dengan canggihnya. Misalnya organisasi, perusahaan maupun instansi yang dimudahkan berkat hadirnya teknologi informasi. Bentuk teknologi informasi yang dimaksud adalah sistem informasi, khususnya yang berbasis website. Kebutuhan akan sistem informasi kini semakin diprioritaskan karena memudahkan setiap manusia dalam menjalankan aktivitas pekerjaannya. Hampir semua bidang telah menggunakan sistem informasi berbasis website, khususnya pada Instansi Pemerintahan.

Dengan menggunakan sistem informasi akan memudahkan dalam mengolah data, menyimpan data dalam database, menghasilkan informasi, serta mencari kembali data yang dibutuhkan. Itulah salah satu alasan bagi instansi pemerintah dalam mengolah data-data agar menghasilkan informasi yang cepat, tepat dan akurat. Hal ini juga menjadi penyebab instansi pemerintah mengganti cara manual atau Microsoft Excel sebagai media untuk mengolah dan menyimpan data karena hasil yang diperoleh kurang akurat. Meskipun sudah banyak instansi yang menggunakan sistem informasi dalam mengolah data, masih terdapat instansi yang menggunakan cara manual dan

program Microsoft Excel sebagai penyimpanan data, seperti Kecamatan Curug yaitu tempat penelitian yang dilakukan penulis.

Kecamatan Curug merupakan instansi pemerintah yang diberikan tugas oleh Dinas Pemerintah Kabupaten untuk menyalurkan Bantuan Pangan Non Tunai (BPNT) kepada warga miskin, dengan jumlah data warga yang terdaftar mencapai lebih dari 1400 peserta menjadikan Kecamatan Curug sebagai peran paling penting dalam mensukseskan program BPNT, terutama tugas Pendamping dan Staff Kecamatan dalam mengolah data warga harus dilakukan dengan sangat teliti dan hati-hati.

Data warga yang banyak diolah menggunakan program Microsoft Excel. Karena laporan yang dihasilkan saat ini belum akurat, masih terdapat banyak kesalahan pada data peserta, banyak terjadi redudancy data dikarenakan kesalahan saat menginput. Hasil laporan tidak terkelompok membuat petugas mengalami kesulitan saat ingin mencari dan memperbaiki kesalahan data. Selain itu sering tejadi kehilangan data serta sulitnya Staff Kecamatan untuk mengetahui informasi laporan data BPNT karena keterlambatan dalam pembuatan laporan dari Pendamping BPNT. Hal tersebut membuat kinerja petugas menjadi terhambat dalam menyalurkan Bantuan Pangan Non Tunai.

\section{METODOLOGI PENELITIAN}

Metode yang di gunakan untuk mendapatkan informasi dan data - data yang diperlukan ditunjukkan pada gambar 1.

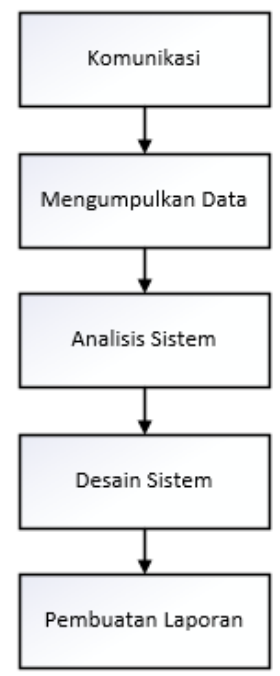

Gambar 1. Metode Penelitian

\section{HASIL DAN PEMBAHASAN}

\subsection{Gambaran Sistem Yang Berjalan}

Berdasarkan hasil pengamatan yang penulis lakukan di Kecamatan Curug, sistem informasi pengolahan data Peserta Bantuan Pangan Non Tunai yang berjalan menggunakan Microsoft Excel. Data Warga miskin yang terbilang cukup besar diolah menggunakan Microsoft Excel baik untuk proses penginputan data dan pembaruan data peserta serta pembuatan laporan. 
Dalam proses penginputan data menyita banyak waktu dan terkadang mengalami redudancy data akibat kesalahan (human error) pada saat menginput data, hal ini menyebabkan data yang diolah menjadi tidak akurat. Dalam proses pembaruan data hasil survey, pendamping membuat laporan hasil survey kemudian diserahkan kepada Staff Pemberdayaan Masyarakat untuk diinput kembali kedalam Microsoft Excel. Kegiatan ini cukup menyita waktu pendamping, karena harus mondar-mandir mengantarkan laporan ke Kecamatan.

Selain itu masalah juga timbul dari Pendamping, dalam Menjalankan Tiap tugasnya harus menunggu data dari Staff Kecamatan untuk survey ke setiap tempat dan sulitnya Staff Kecamatan untuk mengetahui informasi laporan data hasil survey dari pendamping.

\subsection{Prosedur Sistem Yang Berjalan}

Prosedur sistem yang berjalan saat ini pada objek penelitian adalah sebagai berikut:

1) Staff merekap dan menyimpan laporan data warga yang diberikan Dinas Pemerintah kedalam Microsoft Excel;

2) Hasil rekap data Warga diserahkan ke Pendamping untuk disurvey antara data BDT 2015 dengan data hasil survey dilapangan;

3) Pendamping mencatat dan membuat hasil laporan survey menggunakan Microsoft Excel kemudian dicetak dan diserahkan kepada Staff;

4) Staff mencocokkan antara data sebelumnya dengan hasil laporan Pendamping kemudian data diperbarui menggunakan Microsoft Excel;

5) Staff membuat daftar penerima BPNT sesuai hasil survey kemudian data dicetak dan diserahkan ke pendamping untuk dilakukan pembagian BPNT;

6) Warga menerima bantuan dan menandatangani daftar penerima BPNT

7) Pendamping menyerahkan hasil laporan daftar penerima BPNT kepada Staff;

8) Staff membuat laporan hasil survey dan laporan hasil pembagian BPNT menggunakan Microsoft Excel;

9) Staff menyerahkan hasil rekapan laporan akhir peserta bpnt kepada camat untuk diarsipkan.

Prosedur tersebut digambarkan dengan diagram Flowchart yang ditunjukkan pada gambar 2. Flowchart merupakan penggambaran secara grafik dari langkah-langkah dan urutan prosedur suatu program, Biasanya mempengaruhi penyelesaian masalah yang khusunya perlu dipelajari dan dievaluasi lebih lanjut [1].

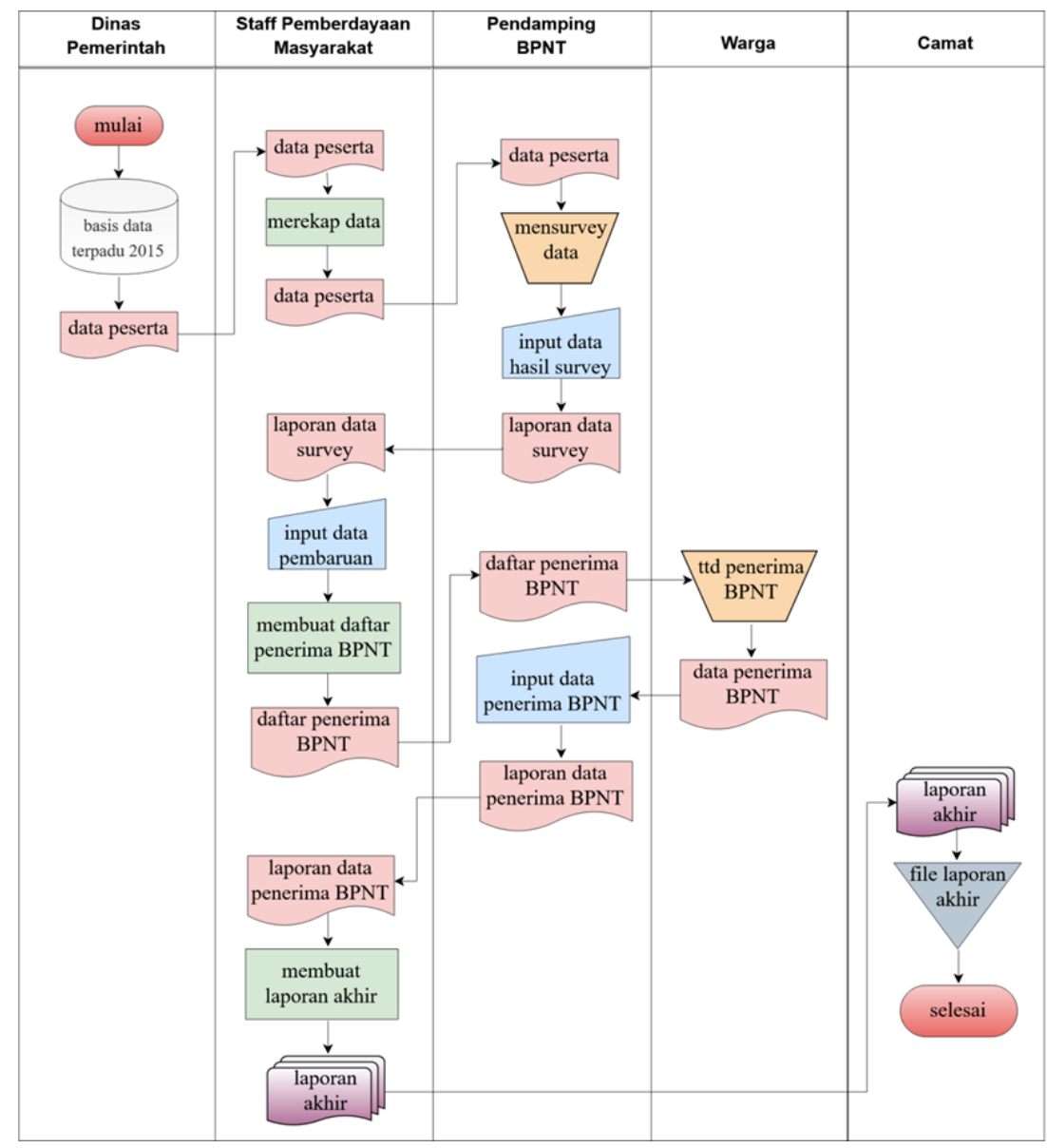

Gambar 2. Flowchart Sistem yang Berjalan 


\subsection{Masalah Yang Dihadapi}

Laporan yang dihasilkan saat ini belum akurat, masih terdapat banyak kesalahan pada data peserta, banyak terjadi redudancy data dikarenakan kesalahan saat menginput. Hasil laporan tidak terkelompok membuat petugas mengalami kesulitan saat ingin mencari dan memperbaiki kesalahan data. Selain itu sering terjadi kehilangan data serta sulitnya Staff Kecamatan untuk mengetahui informasi laporan data BPNT karena keterlambatan dalam pembuatan laporan dari Pendamping BPNT. Hal tersebut membuat kinerja petugas menjadi terhambat dalam menyalurkan Bantuan Pangan Non Tunai.

\subsection{Kekurangan Sistem Yang Berjalan}

1) Menyebabkan resiko kesalahan pengetikan saat penginputan data peserta BPNT karena kurang kecermatan dan ketelitian dari operator

2) Proses penginputan secara manual entry menyita waktu dan kurang efektif

3) Kemungkinan kehilangan data cukup besar karena tidak dibackup dengan baik

4) Pencarian laporan yang ingin dilihat tiap periode kurang tepat karena urutan data yang tidak terkelompok dengan baik

\subsection{Rancangan Sistem Usulan}

\subsubsection{Use Case Usulan}

Use case merupakan pemodelan untuk kelakuan (behavior) sistem informasi yang akan dibuat [2]. Sistem yang diusulkan untuk mengatasi masalah yang ada digambarkan dengan diagram usecase yang ditunjukkan pada gambar 3 .

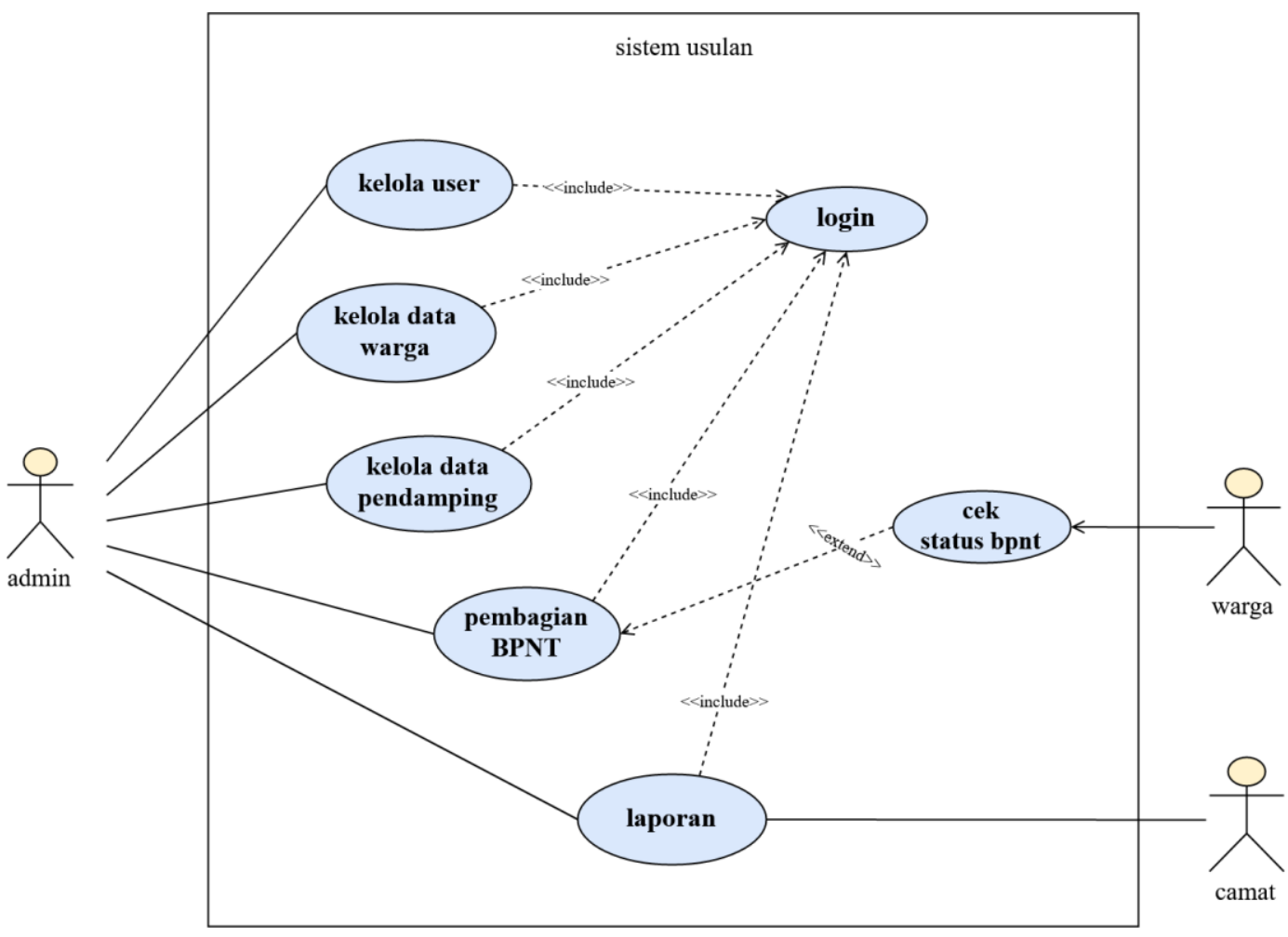

Gambar 3. Use Case Diagram Usulan 


\subsubsection{Statechart Diagram}

Statechart Diagram memperlihatkan urutan keadaan sesaat yang dilalui sebuah obyek, kejadian yang menyebabkan sebuah transisi dari satu state atau aktivitas kepada yang lainnya, dan aksi yang menyebabkan perubahan satu state [3]. Beberapa Statechart diagram yang dibuat untuk menjelaskan sistem yang diusulkan ditunjukkan pada gambar 4.
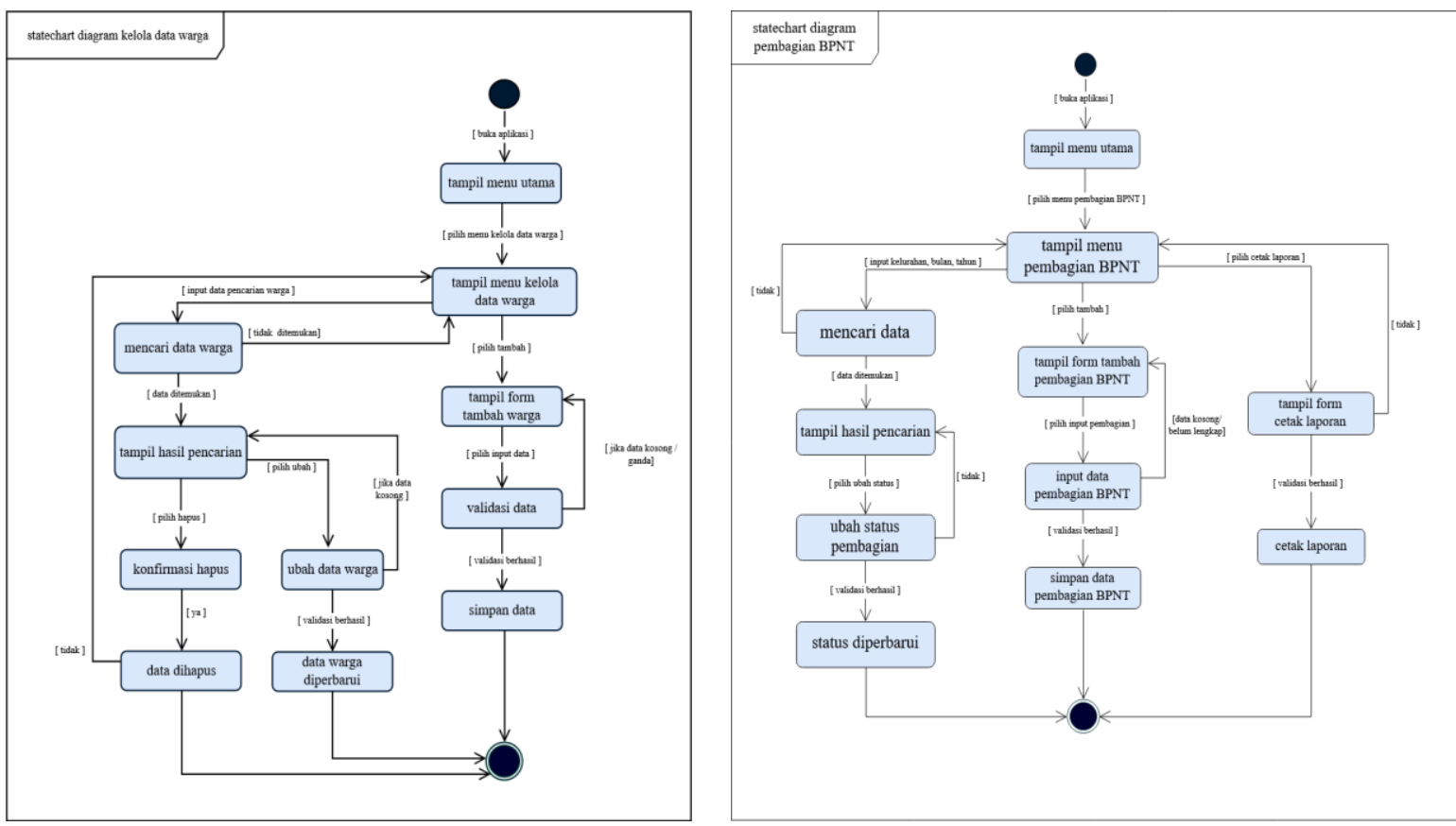

Gambar 4. Statechart Diagram dari Sistem yang Diusulkan

\subsubsection{Activity Diagram}

Activity diagram menggambarkan workflow (aliran kerja) atau aktivitas dari sebuah sistem atau proses bisnis atau menu yang ada pada perangkat lunak [3]. Beberapa activity diagram yang dibuat untuk menjelaskan sistem yang diusulkan ditunjukkan pada gambar 5.

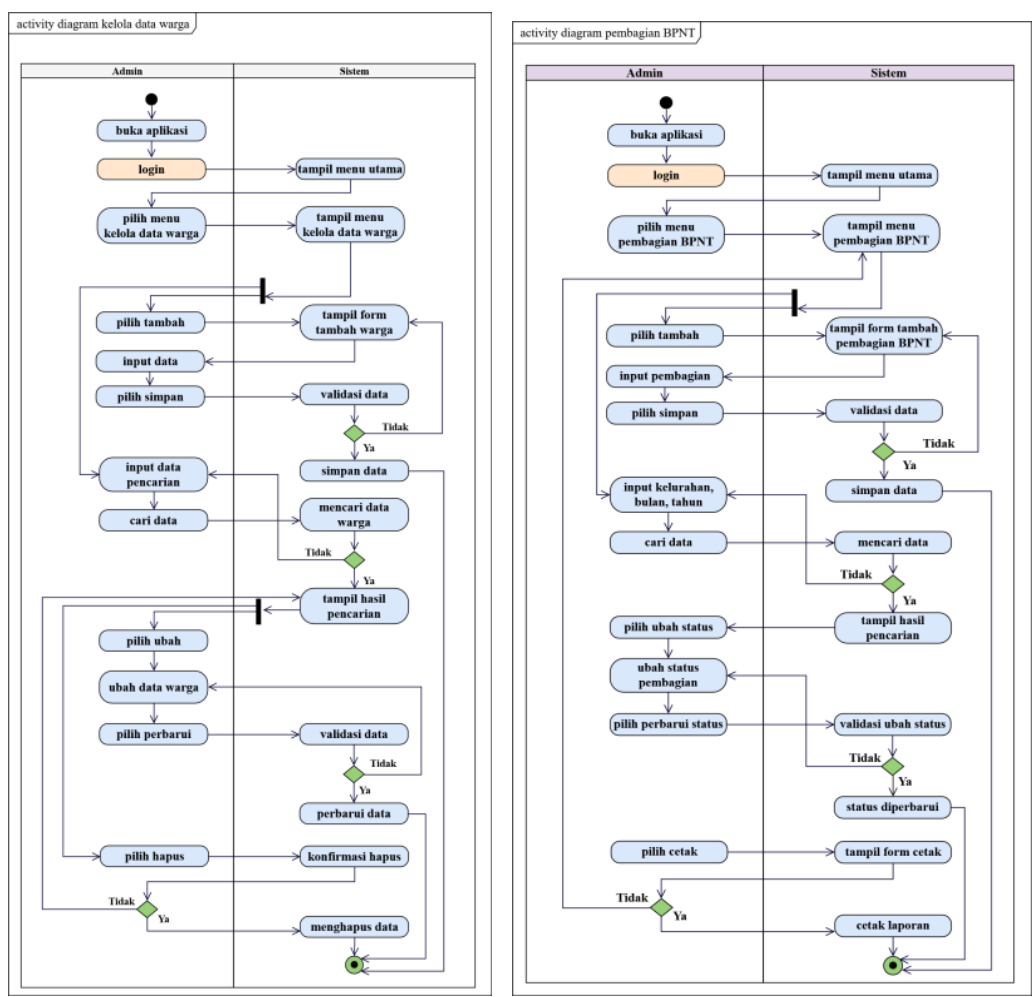

Gambar 5. Activity Diagram dari Sistem yang Diusulkan 


\subsubsection{Tampilan Aplikasi}

Salah satu contoh tampilan aplikasi yang dihasilkan, ditunjukkan pada gambar 6 .

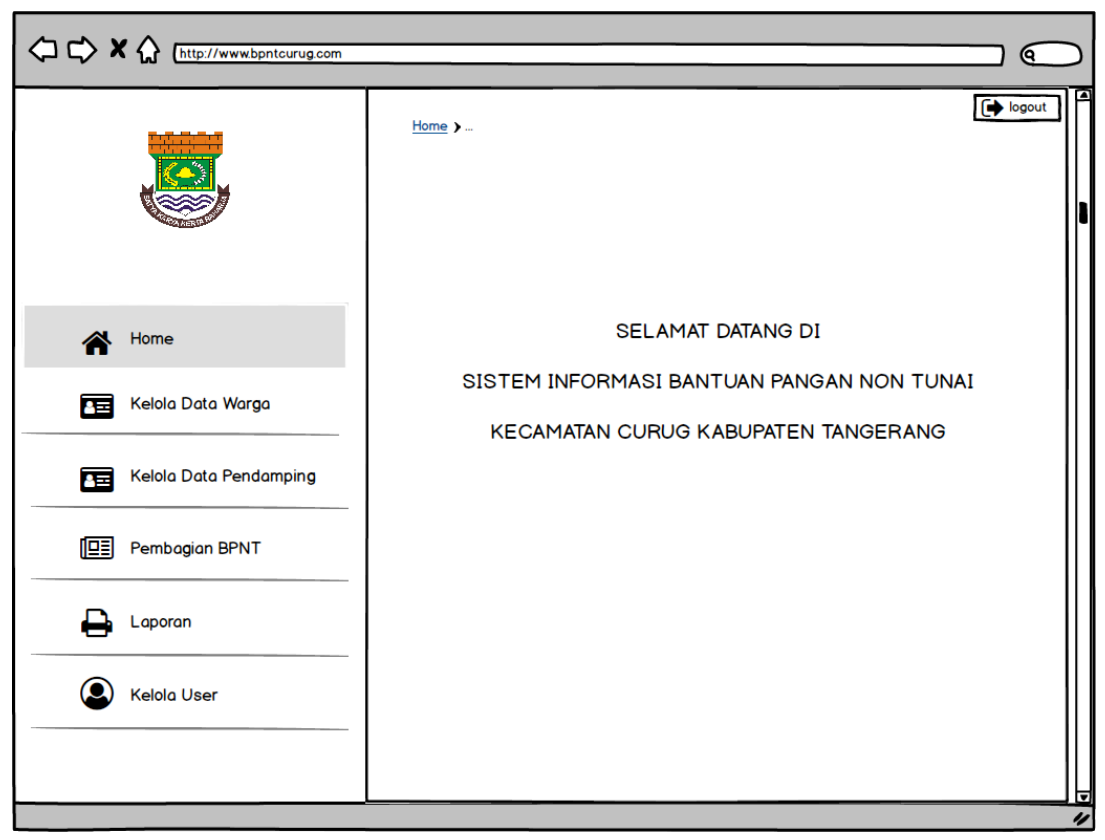

\section{Gambar 6. Tampilan Menu Utama}

\subsubsection{Keunggulan Sistem Usulan}

1) Sistem dapat mensortir data dengan fitur yang tersedia, seperti pembagian Bantuan Pangan Non Tunai berdasarkan Wilayah Kelurahan;

2) Sistem dapat mengolah dan memperbarui data survey untuk admin secara up to date;

3) Staff Pemberdayaan Masyarakat dan Pendamping BPNT dapat membagikan Informasi peserta BPNT dengan mudah dan cepat kepada Camat dan Warga;

4) Warga dapat langsung melihat status penerimaan bantuan melalui aplikasi sistem.

\section{KESIMPULAN}

Berdasarkan hasil penelitian yang dilakukan pada Kecamatan Curug, maka dapat disimpulkan sebagai berikut:

1) Sistem yang berjalan sudah terkomputerisasi namun masih menggunakan Microsoft Excel, kendalanya sering terjadi kehilangan data. Selain itu terdapat banyak kesalahan pada data peserta saat proses penginputan, ini menyebabkan laporan data yang dihasilkan kurang tepat dan akurat.

2) Dengan adanya sistem rancangan usulan berbasis web ini berharap agar mempermudah Pedamping dan Staff Kecamatan dalam melakukan pendataan warga, pendamping tanpa harus datang langsung ke Kecamatan untuk mengantar laporan survey dan untuk mempermudah Staff Kecamatan dalam mengolah data pembagian bantuan pangan.

3) Dengan adanya rancangan usulan ini agar mempermudah admin dalam mencari data arsip laporan BPNT dengan cepat.

4) Rancangan sistem usulan ini dapat menyimpan laporan BPNT yg meliputi data warga, pendamping, dan data pembagian bantuan pangan.

\section{DAFTAR PUSTAKA}

[1] Sutedja, Indrajani. 2011. Perancangan Basis Data All in 1. Jakarta: Alex Media Komputindo.

[2] Ariani Sukamto, Rosa dan M. Shalahuddin. 2013. Rekayasa Perangkat Lunak Terstruktur dan Berorientasi Objek. Bandung: Informatika.

[3] Sholiq. 2006. Pemodelan Sistem Informasi Berorientasi Objek Dengan UML. Yogyakarta: Graha Ilmu. 